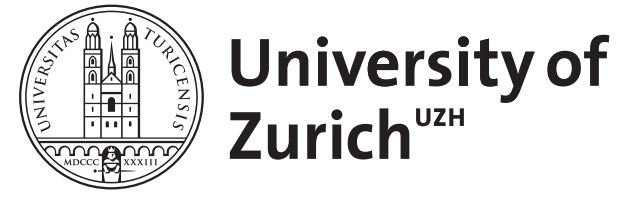

Zurich Open Repository and Archive

University of Zurich

University Library

Strickhofstrasse 39

CH-8057 Zurich

www.zora.uzh.ch

Year: 2013

\title{
Off-pump or on-pump coronary-artery bypass grafting
}

Emmert, Maximilian Y ; Salzberg, Sacha P

DOI: https://doi.org/10.1056/NEJMc1306329SA3

Posted at the Zurich Open Repository and Archive, University of Zurich

ZORA URL: https://doi.org/10.5167/uzh-91469

Journal Article

Published Version

Originally published at:

Emmert, Maximilian Y; Salzberg, Sacha P (2013). Off-pump or on-pump coronary-artery bypass grafting.

New England Journal of Medicine, 369(2):194-195.

DOI: https://doi.org/10.1056/NEJMc1306329SA3 


\section{O R R E S P O N D N C E}

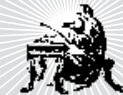

\section{Off-Pump or On-Pump Coronary-Artery Bypass Grafting}

TO THE EDITOR: In the CABG Off or On Pump Revascularization Study (CORONARY) described by Lamy et al. (March 28 issue), ${ }^{1}$ the investigators used the approach of an expertise-based, randomized, controlled trial. ${ }^{2}$ The qualified surgeons were those with more than 2 years of experience after residency training who had completed more than 100 cases of the specific technique. Lamy and colleagues also emphasized that "trainees were not allowed to be the primary surgeon."

But the authors do not specify who harvested saphenous-vein grafts. In many centers, trainees are the primary surgeons for this procedure. Graft harvesting is an important part of the coronaryartery bypass grafting (CABG) operation. One study showed that rates of vein-graft failure were higher among patients with poor-quality grafts, and vein-graft failure was associated with repeat revascularization. ${ }^{3}$

Xiaoning Sun, M.D.

Chunsheng Wang, M.D.

Zhongshan Hospital

Shanghai, China

wang.chunsheng@zs-hospital.sh.cn

No potential conflict of interest relevant to this letter was reported.

1. Lamy A, Devereaux PJ, Dorairaj P, et al. Effects of off-pump and on-pump coronary-artery bypass grafting at 1 year. $\mathrm{N}$ Engl $\mathrm{J}$ Med 2013;368:1179-88.

2. Devereaux PJ, Bhandari $M$, Clarke $M$, et al. Need for expertise based randomized controlled trials. BMJ 2005;330:88.

3. Lopes RD, Mehta RH, Hafley GE, et al. Relationship between vein graft failure and subsequent clinical outcomes after coronary artery bypass surgery. Circulation 2012;125:749-56.

DOI: 10.1056/NEJMc1306329

\section{THIS WEEK'S LETTERS}

194 Off-Pump or On-Pump Coronary-Artery Bypass Grafting

197 Progressive Multifocal Leukoencephalopathy Associated with Ruxolitinib
TO THE EDITOR: Diegeler et al. (March 28 issue) ${ }^{1}$ found no superiority of the off-pump CABG technique over the on-pump technique in an elderly population. The number of crossovers in this study highlights how frequently the initial surgical plan changes.

To address this issue, the authors performed an intention-to-treat analysis to evaluate the effect of treatment assignment and a per-protocol analysis (excluding the patients who crossed over from the assigned treatment). However, these types of analyses, which evaluate the results according to treatment assignment or adherence to the protocol, are not the best way to assess outcome, because CABG is a treatment that is either performed or not performed; this situation is not analogous to prescribing a medication over the long term, with uncertainty regarding the patient's compliance with the assigned treatment.

In our view, the authors should have presented an "as-treated" analysis based on the operation actually performed, and the patients who crossed over from the assigned treatment should not have been excluded.

Filippo Sanfilippo, M.D., Ph.D.

Cristina Santonocito, M.D.

Marc O. Maybauer, M.D., Ph.D.

Oxford Heart Centre

Oxford, United Kingdom

filipposanfi@yahoo.it

No potential conflict of interest relevant to this letter was reported.

1. Diegeler A, Börgermann J, Kappert U, et al. Off-pump versus on-pump coronary-artery bypass grafting in elderly patients. N Engl J Med 2013;368:1189-98.

DOI: 10.1056/NEJMc1306329

TO THE EDITOR: The article by Diegeler et al. comparing outcomes after on-pump CABG with outcomes after off-pump CABG once again shows that off-pump CABG is an excellent therapy. 
However, the statement by Diegeler and colleagues that "technical details were left to the discretion of the operating surgeon" is disappointing, since no information was provided on important details that may have affected early results. The guidelines on myocardial revascularization published by the European Society of Cardiology and the European Association for Cardio-Thoracic Surgery recommend intraoperative graft assessment, ${ }^{1}$ since it is known that surgical revision may be necessary in certain cases. Such assessment is not mentioned. In addition, antithrombotic management is not reported. In our view, this lack of standardization in the off-pump CABG group is a limitation and may explain why repeat revascularization was the only significant difference reported between the two groups $(1.3 \%$ with off-pump CABG vs. $0.4 \%$ with on-pump CABG).

Finally, despite the fact that 37 high-risk patients crossed over to off-pump CABG because of a calcified ascending aorta, the stroke rate was still high among patients who underwent offpump CABG (2.2\%). It is established that systematic application of "anaortic" techniques (i.e., offpump CABG without aortic manipulation) reduces the rate of stroke to less than $1 \%,,^{2-4}$ but no information about aortic management was provided.

Maximilian Y. Emmert, M.D.

University Hospital

Zurich, Switzerland

Sacha P. Salzberg, M.D

Academic Medical Center

Amsterdam, the Netherlands

sacha.salzberg@gmail.com

No potential conflict of interest relevant to this letter was reported.

1. Wijns W, Kolh P, Danchin N, et al. Guidelines on myocardial revascularization. Eur Heart J 2010;31:2501-55.

2. Emmert MY, Salzberg SP, Seifert B, et al. Clampless offpump surgery reduces stroke in patients with left main disease. Int J Cardiol 2012 June 21 (Epub ahead of print).

3. Emmert MY, Seifert B, Wilhelm M, Grunenfelder J, Falk V, Salzberg SP. Aortic no-touch technique makes the difference in off-pump coronary artery bypass grafting. J Thorac Cardiovasc Surg 2011;142:1499-506. [Erratum, J Thorac Cardiovasc Surg 2012;143:995.]

4. Keeling WB, Halkos ME, Puskas JD. Management of patients with a calcified aorta or low ejection fraction undergoing multivessel coronary revascularization. Semin Thorac Cardiovasc Surg 2010;22:250-2.

DOI: $10.1056 /$ NEJMc1306329

TO THE EDITOR: Diegeler et al. state: "Our trial does not support the assumption that off-pump CABG can improve the early outcome in highrisk patients." In this statement, the authors overlook the fact that the rates of death in their study $(2.6 \%$ among the patients who underwent off-pump CABG and $2.8 \%$ among the patients who underwent on-pump CABG at 30 days) are much lower than the rates of death among patients in the off-pump group that were predicted by the two risk scores used $(8.3 \%$ according to the European System for Cardiac Operative Risk Evaluation [euroSCORE] ${ }^{1}$ and $3.8 \%$ according to the German coronary score ${ }^{2}$ ).

The euroSCORE is based on 18 independent risk variables, not all of which were specifically reported in the study by Diegeler et al. In our opinion, the reported variables suggest that the patients in the study were not at high operative risk. Among the patients in the off-pump group, only $1.9 \%$ were in critical condition, $2.2 \%$ had a creatinine level greater than $2.3 \mathrm{mg}$ per deciliter (203.3 $\mu \mathrm{mol}$ per liter), 2.1\% had a left ventricular ejection fraction that was less than 30\%, 3.7\% had class IV angina according to the Canadian Cardiovascular Society scale (ranging from I to IV, with higher classes indicating greater limitations on physical activity owing to angina), $0.9 \%$ received renal-replacement therapy, and only $3.3 \%$ had pulmonary arterial hypertension.

Giovanni Saeed, M.D.

Michael Möller, M.D.

Rainer Gradaus, M.D., Ph.D.

Klinikum Kassel

Kassel, Germany

dr.gsaeed@web.de

No potential conflict of interest relevant to this letter was reported.

1. Nashef SA, Roques F, Micheal P, Gauducheau E, Lemeshow S, Salomon R. European system for cardiac operative risk evaluation (EuroSCORE). Eur J Cardiothorac Surg 1999;16:9-13.

2. Badreldin AMA, Kania A, Ismail MMA, et al. KCH, the German preoperative score for isolated coronary artery bypass surgery: is it superior to the logistic EuroSCORE? Thorac Cardiovasc Surg 2011;59:399-405.

DOI: $10.1056 / N E J M c 1306329$

TO THE EDITOR: Two trials of off-pump CABG confirm its lack of superiority over on-pump CABG and provide support for skepticism about its role. ${ }^{1}$ Subtle benefits - fewer transfusions and possibly fewer strokes - have been shown in some studies by experts, but they are scanty in less experienced hands except in highly specific situations. Patients in studies with less carefully selected surgeons require more repeat revascularizations. ${ }^{2}$

In the accompanying editorial, Alexander ${ }^{3}$ discusses the "learning curve" for the use of off- 
pump CABG and suggests limiting its use "to surgeons who are experienced with off-pump techniques." But experienced surgeons come from inexperienced ones, and it is patients who are subject to the learning curve. When improved surgical procedures replace outdated ones, the disparities between the results with expert surgeons as compared with inexpert surgeons are unavoidable, but what if the new technique has minimal, if any, advantages?

On-pump CABG is a refined, extensively proven approach performed by vast numbers of experienced surgeons. Nevertheless, the use of offpump CABG remains widespread and is marketed aggressively to a demanding public. Considering the difficulty in gaining supervised experience after residency training, can inexperienced surgeons justify seeking expertise in off-pump CABG while subjecting patients to a learning curve?

Lawrence I. Bonchek, M.D.
Lancaster General Health
Lancaster, PA
libonchek@comcast.net
$\quad$ No potential conflict of interest relevant to this letter was re-
ported.

1. Bonchek LI. Off-pump coronary bypass: is it for everyone? J Thorac Cardiovasc Surg 2002;124:431-4.

2. Shroyer AL, Grover FL, Hattler B, et al. On-pump versus offpump coronary-artery bypass surgery. N Engl J Med 2009;361: 1827-37.

3. Alexander JH. Clinical-outcome trials in cardiac surgery have we primed the pump? N Engl J Med 2013;368:1247-8.

DOI: 10.1056/NEJMc1306329

DR. LAMY AND COLleagues REPLY: We agree with Sun and Wang on the importance of the performance of surgical trials by expert surgeons to avoid potential biases toward the easiest or most frequently performed surgical technique. CORONARY is an expertise-based, randomized trial, and the test of expertise at the beginning of the trial ( 2 years of experience after residency training and completion of more than 100 cases of the specific technique) was directed to the surgeons performing the operations in view of the magnitude of their involvement and the effect of their skills on the surgery. Other members of the operating team, such as anesthetists, perfusionists, vein harvesters, and nursing staff on the ward, also played an important role in the care of patients, but they were not subjected to the same expertise test. However, all 79 centers that partici- pated in our trial were large cardiac centers with experience in both techniques, and they perform hundreds of CABG procedures every year. Therefore, it seems unlikely that a potential bias related to the vein harvesting or the performance of other team members could be introduced and could have influenced the results of our trial.

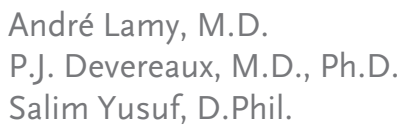

Population Health Research Institute Hamilton, ON, Canada

lamya@mcmaster.ca

Since publication of their article, the authors report no further potential conflict of interest.

DOI: 10.1056/NEJMc1306329

DR. Diegeler AND Colleagues Reply: Saeed et al. correctly stated that mortality among patients in our trial was lower than that predicted by the applied risk scores. This finding does not contradict the increased operative risk of the study population. The rationale for including patients 75 years of age or older was that there is a higher risk of adverse events and consequently a higher event rate among these patients. This inclusion criterion allowed the definition of a distinct and large enough patient sample. When grouped according to German coronary score quartiles, the frequency of the primary end point (a composite of death or a major adverse event within 30 days and within 12 months after surgery) across all quartiles was similar between patients who underwent on-pump CABG and those who underwent off-pump CABG (Table 1).

We share some of the objections raised by Sanfilippo et al. regarding the intention-to-treat analysis of a surgical procedure, yet the proposed "as-treated" analysis including the patients who crossed over is not adequate and would introduce substantial bias. Given the increased event rate among patients who crossed over from the assigned treatment, ${ }^{1,2}$ such an approach would blame the competing procedure (notably onpump (ABG) for the failure of the other.

The comments by Emmert and Salzberg point to the area of conflict between the feasibility of investigating a complex procedure in a multicenter trial and the control of every factor that could potentially influence the outcome. Given that there is no generally established "best" 
technique and that centers and surgeons were selected because of their experience, details about antithrombotic management and flow measurement were indeed left to the discretion of each surgeon and center. When the group of patients assigned to off-pump CABG was divided according to the use or nonuse of aortic manipulation (255 patients underwent the procedure with the anaortic technique, 277 with an anastomotic device, and 655 with partial aortic occlusion (clamping), rates of stroke were similar in each group $(2.4 \%$ with the anaortic technique, $1.8 \%$ with the anastomotic device, and $2.3 \%$ with clamping.

Bonchek asks whether it is justified to put patients at risk while gaining expertise in offpump CABG without a proven benefit of the procedure. Avoidance of a "learning curve" is a challenge for clinical researchers, especially in the surgical arena. We now know that off-pump CABG has excellent results when performed by expert surgeons. If studies showed a benefit of off-pump CABG performed by expert surgeons, the consequence would be that all other surgeons would need to follow and adapt the offpump technique with all necessary efforts for training under a strict quality control. The aim of randomized trials is to investigate whether or not there is a need for a paradigm change.

Anno Diegeler, M.D., Ph.D.

Wilko Reents, M.D.

Michael Zacher, M.D.

Herz- und Gefäss-Klinik Bad Neustadt

Bad Neustadt, Germany

cachir@herzchirurgie.de

Since publication of their article, the authors report no further potential conflict of interest.

1. Mukherjee D, Ahmed K, Baig K, Patel VM, Darzi A, Athaasiou T. Conversion and safety in off-pump coronary artery bypass: a system failure that needs re-emphasis. Ann Thorac Surg 2011;91:630-9.

2. Patel NC, Patel NU, Loulmet DF, McCabe JC, Subramanian
Table 1. Frequency of the Composite Primary End Point, According to Quartile of German Coronary Score.*

$\begin{array}{llll}\text { Variable } & \begin{array}{c}\text { On-Pump } \\ \text { CABG } \\ \text { no. of patients/total no. (\%) }\end{array} & \begin{array}{c}\text { Off-Pump } \\ \text { CABG }\end{array} & \begin{array}{c}\text { Odds Ratio } \\ (\mathbf{9 5 \%} \text { CI) }\end{array} \\ \text { Quartile 1 } & 12 / 296(4.1) & 10 / 272(3.7) & 0.95(0.46-1.99) \\ \text { Quartile 2 } & 24 / 314(7.6) & 21 / 322(6.5) & 0.84(0.46-1.53) \\ \text { Quartile 3 } & 22 / 287(7.7) & 21 / 307(6.8) & 0.85(0.47-1.55) \\ \text { Quartile 4 } & 41 / 310(13.2) & 41 / 286(14.3) & 1.12(0.70-1.78)\end{array}$

* German coronary scores range from 0 to 100, with higher scores indicating greater risk. CABG denotes coronary-artery bypass grafting, and $\mathrm{Cl}$ confidence interval.

VA. Emergency conversion to cardiopulmonary bypass during attempted off-pump revascularization results in increased morbidity and mortality. J Thorac Cardiovasc Surg 2004;128:655-61.

DOI: $10.1056 / N E J M c 1306329$

THE EDITORIALIST REPLIES: Bonchek raises an important point about how a person gains experience in either off-pump or on-pump CABG surgery. Training in new surgical techniques that do not provide a proven benefit, such as the offpump CABG technique, should ideally be conducted in established training programs that provide appropriate oversight and supervision from experienced surgeons. This is probably true not only for off-pump CABG surgery but for other procedures as well.

Data from empirical research are currently lacking on the experience necessary to both develop and maintain expertise in cardiac and other surgical procedures.

John H. Alexander, M.D., M.H.S.

Duke Clinical Research Institute

Durham, NC

Since publication of his article, the author reports no further potential conflict of interest.

DOI: 10.1056/NEJMc1306329

\section{Progressive Multifocal Leukoencephalopathy Associated with Ruxolitinib}

TO THE EDITOR: Ruxolitinib, an inhibitor of Janus kinases (JAKs) 1 and 2, has been approved in the United States and Europe for the treatment of myelofibrosis. ${ }^{1}$ We report a case of progressive multifocal leukoencephalopathy (PML) in a patient with myelofibrosis after initiation of ruxolitinib therapy.

A 75-year-old man with intermediate-2-risk 